\title{
Psychoses in drug-resistant temporal lobe epilepsy
}

\author{
I N G E J E NSEN A N D J K K L A R S E N \\ From the University Clinics of Neurosurgery and Psychiatry, Rigshospitalet, Copenhagen \\ and University Clinic of Neurology, Glostrup Hospital, Denmark
}

S UMMARY In the survey of 74 Danish patients with temporal lobe epilepsy who underwent temporal lobectomy, a total of 20 patients were psychotic. Nine of these became psychotic during the follow-up period, six of them after cessation of their epileptic seizures. There were 13 schizophrenia-like psychoses, six paranoid delusional and depressive psychoses, and one childhood psychosis. Operation was on the right side in 39 and on the left side in 35 patients. When the various psychotic groups were compared with each other or with the nonpsychotic patients, the side of operation was not found to be statistically important. The patients with psychoses were older at operation and showed a higher rate of focal lesions in the resected specimens. Although more psychotic patients were bright or normally gifted, and had achieved a higher standard of schooling than nonpsychotic patients, their social status after operation was inferior. Surgery had no effect on psychosis present preoperatively nor on its possible postoperative onset. The diagnosis of psychosis was not considered to be a contraindication to temporal lobectomy.

An association between epilepsy and psychosis has been recognised since the nineteenth century (Davidson and Bagley, 1969; Köhler, 1973; Bruens, 1974). A possible relationship between epilepsy and affective disorders was examined in only a few cases (Flor-Henry, 1969a, b), whereas most studies were directed at the relationship between epilepsy and schizophrenia.

For many years these two disorders were thought to show an inverse relationship (Krapf, 1928; Glaus, 1931; Gruhle, 1936; von Meduna, 1937; Yde et al., 1941), although both were often diagnosed concurrently in a patient.

Generally the psychosis was preceded by epileptic seizures over several years (Gruhle, 1936; Rodin et al., 1957) and occurred when the epilepsy was in remission (Glaus, 1931). This view was supported by the electrophysiological studies of Landholt (1960), who described onset of or worsening of existing psychosis in relation to a normalisation or almost normalisation of the EEG in temporal lobe epileptics ("forced normalisation").

Slater and Beard $(1963 a, b)$ in their comprehensive writings based on the observations of Hill (1953) and Pond (1957) reformulated the

Address for reprint requests: Dr I. Jensen, University Clinic of Neurology, Glostrup Hospital, 2600 Glostrup, Denmark. The authors will also provide on request a table on various clinical manifestations of psychotic and nonpsychotic patients.

Accepted 10 April 1979 nosography of the schizophrenia-like psychoses of epilepsy. They found no evidence against the hypothesis that epilepsy was aetiologically related to the psychoses. This concept was developed by Flor-Henry (1969b) who claimed that the presence of psychomotor seizures and frequent temporal fits were universely correlated with psychoses, suggesting that such seizures and psychoses were manifestations of the same underlying disturbance of cerebral function. Falconer and Serafetinides (1963) and Taylor (1972) suggested that temporal lobe epilepsy and schizophrenia-like psychoses were associated but different entities each of which followed its own cause, although both were localised in the temporal lobe. Lastly Bruens (1974) regarded the causes of psychoses as multifactorial.

Few surveys of surgical management report in detail cases of schizophrenia-like illness which have occurred (Paillas, 1958; James, 1960; Bailey, 1961; Falconer and Serafetinides, 1963; Green and Scheetz, 1964; Bein and Boreiko, 1972; Taylor, 1972).

The present investigation aims to record the incidence and clarify the aetiology and underlying neuropathology of the psychoses associated with cpilepsy by corrclating the psychosis with various clinical parameters.

Fisher's Exact Test (the Vierfelder Test) is the statistical test generally applied with the 
significance level at $5 \%(\mathrm{P}<0.05)$. If the significance is found to be at or below the $1 \%$ level or if other statistical methods are applied, this is specified in the text.

\section{Subjects and methods}

The preliminary case material consisted of 78 patients; four of these (cases 59, 61, 66 and 69) were excluded from the final analysis because of a preoperative diagnosis of tumour.

In the present study we surveyed 20 psychotic patients who were found among 74 consecutive patients with drug-resistant temporal lobe epilepsy and who had undergone unilateral anterior temporal lobe resection at the University Clinic of Neurosurgery, Rigshospitalet, Copenhagen, between 1960 and 1969. All had psychomotor attacks, with or without focal seizures, arising in the temporal lobe, and 17 of the 20 psychotic patients also had grand mal (tonic-clonic seizures). Preoperatively all were socially handicapped by frequent and severe seizures with or without severe psychiatric disturbances. In all the patients a unilateral, or a predominantly unilateral, temporal spike focus was found.

Retrospective follow-up was carried out during 1970-1971 and covered clinical, aetiological, genetic, social, neuropathological, neuroophthalmological, and psychiatric aspects (Jensen, 1975a, b, c, 1976a, b, c, 1977; Jensen and Klinken, 1976; Jensen and Seedorff, 1976; Jensen and Værnet, 1977; Jensen and Larsen, 1979).

Psychiatric assessment was undertaken by one of us (IJ). The preoperative assessments were based exclusively on records including those from the psychiatric departments of other hospitals. The postoperative assessment was a subjective evaluation by $\mathbf{I J}$, which was later confirmed by JKL.

The criteria for inclusion in the group of psychotics were the occurrence, documented in a hospital setting, either of one or more psychotic episodes of a permanent psychosis in a state of clear consciousness. Patients with epileptic twilight states, confusional states, or mood alterations were thus excluded from the survey.

\section{Results}

A total of 20 patients in this Danish survey were described as psychotic. Eleven patients were preoperatively psychotic. After a transient postoperative deterioration, case 9 recovered. She had not displayed any psychiatric abnormalities either at follow-up, or during the three years before operation. A further nine patients became psychotic in the postoperative follow-up period, six of them after apparent cure of their epileptic seizures. All the patients displayed severe behaviour disturbances previous to the onset of the psychoses. Representative case histories were recorded by Jensen and Larsen (1979).

The patients were divided into groups according to the classification of Serafetinides and Falconer (1962).

\section{PARANOID DELUSIONS AND DEPRESSIONS}

These six patients (cases $9,17,39,42,45$, and 54) had a manic-depressive or schizo-affective psychosis and were treated with ECT or tricyclic antidepressants or both at least once. This group included case 9 who had no psychiatric abnormality at follow-up.

\section{SCHIZOPHRENIA-LIKE PSYCHOSES}

Some of these 13 patients (cases 11, 19, 21, 27, $28,35,48,50,51,53,70,72,77)$ displayed acute confusional psychotic episodes within the first postoperative ycar. A few were demented, but not to such an extent as to be classified as having an organic psychosis. Three of the patients were simple schizophrenics while the remaining 10 patients showed the picture of the chronic paranoid state described by Pond (1957) and by Slater and Beard $(1963 a, b)$. "The affect tended to remain warm and appropriate and there was no typical deterioration to the hebephrenic state. On the other hand there was not one of the cardinal symptoms of schizophrenia which was not at sometime exhibited by these patients."

\section{ACUTE CONFUSIONAL PSYCHOTIC EPISODES}

There were no patients in this category.

\section{CHRONIC PSYCHOTIC STATE}

The last patient (case 46) who underwent surgery at the age of $4 \frac{1}{2}$ years, developed a chronic psychotic state during the first postoperative year, dominated by a severe autism.

In $65 \%$ of 19 patients aged 17 years or more, the age at onset of psychosis was above 25 years with a mean age of 27.9 years (Figure). The epileptic seizures preceded the psychotic symptoms (mean 13.7 years) except in case 51. In half of the patients the interval between onset of epilepsy and onset of psychosis exceeded 15 years with a mean prepsychotic duration of epilepsy of 22 years (Figure).

All the patients with psychoses suffered from a variety of psychomotor seizures. Hallucinations or illusions and automatisms of complex nature 


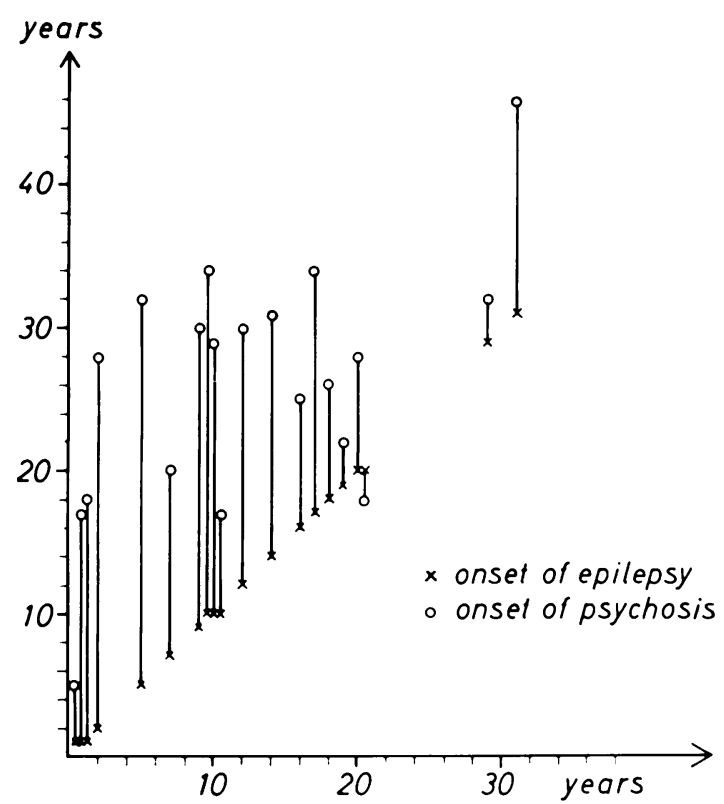

Figure Age at onset of epilepsy versus age at onset of psychosis.

were recorded in more of the psychotic patients than in the patients without psychosis, whereas the latter had a higher prevalence of symptoms from the autonomic nervous system (vegetative symptoms).

The prevalences of grand mal, petit mal, and focal seizures were higher among the psychotic compared with the nonpsychotic patients, possibly indicating a more severe epilepsy in the former group.

Right-handedness and operations on the right or on the nondominant sides were more frequent in psychotic patients but no segregation by handedness or by hemisphere dominance was found when the various psychotic groups were compared with each other.

Patients with psychoses were older at onset of epilepsy compared with nonpsychotic patients. However impressive this trend might appear, it was not statistically significant. Epilepsy was also of longer duration preoperatively in the psychotic group; and the operation was performed at an older age (at or above 30 years) in the psychotic compared with nonpsychotic patients $(60 \%$ and $19 \%$ respectively, the difference being statistically significant at the $0.2 \%$ level $(P=0.0018))$. Age at onset of epilepsy, age at operation, and preoperative duration were the same in patients whose psychoses began before or after surgery.
The outcome of epilepsy after surgery was not statistically related to the presence or absence of psychosis. It was, however, a remarkable and statistically significant observation $(P=0.0241)$ that more cases with a focal neuropathological lesion were found in psychotic patients and a higher incidence of major psychiatric disorders was found in their near relatives, $65 \%$ compared with $39 \%$ in relatives of nonpsychotics. The mothers of both psychotic and nonpsychotic patients experienced an equal number of abnormal pregnancies when carrying the children destined to be epileptic as well as others. On the other hand, psychotic patients had been exposed more of ten to perinatal complications.

Postoperatively more than two-thirds of patients without psychosis improved their overall psychiatric status or became completely normal compared with a similar improvement in only $40 \%$ of psychotic patients. On the other hand, eight of 11 patients with preoperative psychosis improved after surgery.

Of 14 patients attempting suicide on at least one occasion, an equal proportion of psychotic and nonpsychotic patients made their attempt within one year of operation.

Sexual deviations, mostly characterised by impaired drive, have been described previously (Jensen and Larsen, 1979). As expected, more psychotics than nonpsychotics showed such a tendency, which was not significant.

The psychotic patients appeared to be intellectually brighter than the patients without psychoses and consequently more of them achieved a higher level of education. In both groups a transient reduction of intellectual function was often seen in the first year after operation but was usually followed by improvement to a level actually higher than that attained before surgery (unpublished data). The psychotic patients, however, seemed unable to profit from this as only $15 \%$ were working full time at follow-up compared with nearly half the nonpsychotic patients.

The parents of both groups of patients were distributed in similar fashion through the social classes and, as we have shown before (Jensen and Larsen, 1979), all patients tended to descend the social scale, this decline being greater among psychotic patients.

\section{Discussion}

The incidence of psychosis in the present survey is higher than in previously published papers on the surgical treatment of temporal lobe epilepsy 
(Falconer and Serafetinides, 1963; Taylor, 1972; van Buren et al., 1975). Being unable to find reasons for this discrepancy we suppose it may be the result of preoperative selection.

Like Falconer and Serafetinides (1963) and Taylor (1972) we found that temporal lobectomy did not influence the course of paranoid or schizophrenia-like psychoses even in those cases, not infrequently seen, in which psychotic symptoms become less severe after surgery. Burckhardt (1891) was perhaps the first to make this disappointing observation when he tried to relieve two patients, presumably schizophrenic, of their auditory hallucinations. Serafetinides and Falconer (1962), and before them Glees et al. (1950), found that partial excision of the limbic system or of the temporal lobe in schizophrenic patients usually decreased the florid symptoms but left the psychosis untouched. Kendrick and Gibbs (1957) found that more radical excision produced dementia.

When we considered the nosology of the psychoses we began by following Taylor (1972) who described each patient individually. Later we realised that all the Danish patients (except for one case with childhood psychosis) could be classified according to the schema proposed by Serafetinides and Falconer (1962)-thus six patients fell into the group with mainly paranoid delusions and depressions, and 13 into that of schizophrenialike psychoses, while none showed an acute confusional episode. Slater and Beard (1963a) suggested that there were three groups within the schizophrenia-like psychoses and did not segregate the schizo-affective psychoses as a separate group although they mentioned the symptoms of this type of psychosis. Close to Bingley's (1958) finding of depressive mood changes associated with an EEG focus in the recessive temporal lobe and paranoid tendencies with a focus in the dominant temporal lobe, Flor-Henry (1969a, b) not only segregated psychotic manifestations from manicdepressive reactions, but also concluded that epilepsy of the nondominant temporal lobe was associated with manic-depressive disorder whereas epilepsy of the dominant lobe accompanied a schizophrenic illness. Our findings neither disprove nor confirm these earlier reports.

In the present study the mean age at onset of psychosis of 27.9 years was in complete agreement with Slater and Beard (1963a) and with Taylor (1972), but lower than that recorded by Kristensen and Sindrup (1978) who gave a median age of 34 years. Like Taylor (1972) we found that psychotic patients started their epilepsy at a later age than nonpsychotic patients. Pond (1957) was the first to state that patients with chronic epilepsy were well controlled with anticonvulsants when the psychosis began, an observation later confirmed by Flor-Henry (1969a). A similar observation came from Landholt (1960) who described normalisation or improvement of EEG dysrhythmias during the development of a psychosis. Our finding that nine patients became psychotic after temporal lobectomy, including six who were seizure-free, confirmed these reports. The mean duration of 13.7 years between onset of epilepsy and onset of psychosis found in the present study compared well with the 14.1 years recorded by Slater and Beard (1963a) and Taylor (1972). Our observations were also in complete agreement with those of Kristensen and Sindrup (1978).

Taylor (1972) observed that there was a relationship between the types of epileptic attacks and the preoperative mental state. In the present study psychotic patients showed a higher incidence of attacks with hallucination or illusion and of automatisms of a complex nature and grand mal (tonic-clonic) seizures, whereas visceral symptoms were more common among nonpsychotics.

Our findings do not agree with Taylor (1975), Gur (1977), and Kristensen and Sindrup (1978) who all observed a significantly increased frequency of left handers or ambidextrals among the psychotic patients, and accordingly proposed that this might indicate a higher frequency of disturbances of the left cerebral hemisphere. They also disagree with Taylor (personal communication, 1978) who found that the risk of psychosis was maximal in females, sinistrals, and in patients with left sided lesions. On the other hand, we agreed that the presence of focal abnormality- "the alien tissue group"predisposed to psychosis (Taylor and Falconer, 1968; Taylor, 1975).

Operation at a young age facilitated postoperative social rehabilitation (Falconer and Davidson, 1974; Jensen, 1977c). Falconer and Davidson (1974) suggested that psychotic manifestations might be prevented by operating on patients with temporal lobe epilepsy at an earlier stage of their disease. Our results support their advice as significantly more of the older patients (12 of 22 aged 30 years or more at operation) had become psychotic compared with eight of 52 younger patients-55 and $15 \%$ respectively. On the other hand follow-up had not been long enough for all patients to have passed the age at which paranoid schizophrenic and schizophreniclike psychoses were most likely to become clinically apparent (Taylor, 1972). 
In the present case material (Jensen, 1975) the observed incidence of major psychiatric disorders among close relatives is higher than in the general Danish population (Strömgren, 1938; Fremming, 1947). This observation is in full agreement with Taylor (1972). On the other hand, Slater and Glithero (1963) in their 69 patients with schizophrenia-like psychosis associated with epilepsy found only two patients with such a genetic predisposition, a figure not higher than in the general English population, an observation markedly diverging from our finding of 16 out of 20 psychotic patients with a positive psychiatric family history. We have attempted in vain to explain this very marked discrepancy.

An increased rate of perinatal complications in all patients but greater among the psychotic patients, agrees with the findings of Torrey and Peterson (1974). Similarily Kristensen and Sindrup (1978) found that many of their patients had had illnesses which might have caused an epileptogenic lesion, tendency being marked in psychotic cases.

Suicidal tendencies are frequently found in epileptic patients (Delay et al., 1957; Janz, 1969; Taylor, 1977 personal communication). The present study confirms this and also the observation by Janz (1969) that many patients had become seizure-free before committing suicide.

Epilepsy may be associated with some psychological impairment, being found more often with convulsive than with psychomotor seizures, and with an earlier age of onset (Reitan, 1974). This accords with the findings of the present study that intellect was generally reduced preoperatively with only limited improvement after temporal lobectomy. This finding was not restricted to nonpsychotics although they were the intellectually more retarded group. As epilepsy begins later in psychotics (Scott, 1978), they have the chance of more advanced education which seems to benefit them little, as fewer find employment than their less well-endowed nonpsychotic fellow epileptics, despite control of their epilepsy. At follow-up significantly fewer psychotics were in full-time employment compared with nonpsychotics, as reported earlier by Juul-Jensen (1964, 1974), Dennerl et al. (1966) and Rodin (1968).

\section{Conclusion}

Recent Danish studies confirm the value of unilateral anterior temporal lobectomy for patients with temporal lobe epilepsy who have a unilateral, or predominantly unilateral, EEG focus in the temporal lobe and whose epilepsy has proved re- sistant to therapy with anticonvulsants. There is also good reason for surgery at a relatively early age to facilitate social rehabilitation.

The present study, however, shows that operation does not prevent the onset of psychosis nor cure it if already present although it may lessen psychotic symptoms. Psychosis does not of itself contraindicate temporal lobectomy but it may impede social rehabilitation afterwards.

\section{References}

Bailey, P. (1961). Surgical treatment of psychomotor epilepsy. Southern Medical Journal, 54, 299-301.

Bein, B. N., and Boreiko, V. B. (1972). Surgical treatment of patients with temporal epilepsy and marked psychic disorders. Voprosy Neirokhirugii (Russia), 36, 26-31.

Bingley, T. (1958). Mental symptoms in temporal lobe epilepsy and temporal lobe gliomas. Acta Psychiatrica et Neurologica Scandinavica, Supplementum $120,33,1-151$.

Bruens, J. H. (1974). Psychoses in epilepsy. In Handbook of Clinical Neurology, vol. 15, pp. 593-610. Edited by P. J. Vinken and G. W. Bruyn. NorthHolland: Amsterdam.

Burckhardt, G. (1891). Über Rindenexcisionen als Beitrag zur operativen Therapie der Psychosen. Zeitschrift für Psychiatrie und psychisch-gerichtliche Medizin, 47, 463-548.

Davidson, K., and Bagley, C. R. (1969). Schizophrenialike psychoses associated with organic disorders of the central nervous system: review of the literature. In Current Problems in Neuropsychiatry. Schizophrenia, Epilepsy, The Temporal Lobe. British Journal of Psychiatry, Special Publication No. 4, pp. 113-184. Edited by R. N. Herrington. Royal Medico-Psychological Association. Headley Brothers: Ashford, Kent.

Delay, J., Deniker, P., and Baraude, R. (1957). Le suicide des épileptiques. Encéphale, 46, 401-412.

Dennerl, R. D., Rodin, E. A., Gonzáles, S., Schwartz, M. L., and Lin, Y. (1966). Neurological and psychological factors related to employability of persons with epilepsy. Epilepsia, 7, 318-319.

Falconer, M., and Davidson, S. (1974). The rationale of surgical treatment of temporal lobe epilepsy with particular reference to childhood and adolescence. In Epilepsy, pp. 209-214. Edited by P. Harris and C. Mawdsley. Churchill Livingstone: Edinburgh.

Falconer, M. A., and Serafetinides, E. A. (1963). A follow-up study of surgery in temporal lobe epilepsy. Journal of Neurology, Neurosurgery, and Psychiatry, 26, 154-165.

Flor-Henry, P. (1969a). Psychoses and temporal lobe epilepsy. A controlled investigation. Epilepsia, 10, 363-395.

Flor-Henry, P. (1969b). Schizophrenia-like reactions and affective psychoses associated with temporal 
lobe epilepsy: etiological factors. American Journal of Psychiatry, 126, 547-586.

Fremming, K. H. (1947). Sygdomsrisikoen for sindslidelser og andre sjalelige abnormtilstande $i$ den denske gennemsnitsbefolkning, pp. 1-280. Ejnar Munksgaard: København.

Glaus, A. (1931). Über Kombinationen von Schizophrenie und Epilepsie. Zeitschrift für die gesamte Neurologie und Psychiatrie, 135, 450-500.

Glees, P., Cole, J., Whitty, C. W. M., and Cairns, H. (1950). The effects of lesions in the cingular gyrus and adjacent areas in monkeys. Journal of Neurology, Neurosurgery, and Psychiatry, 13, 178-190.

Green, J. R., and Scheetz, D. G. (1964). Surgery of epileptogenic lesions of temporal lobe. Archives of Neurology (Chicago), 10, 135-148.

Gruhle, H. W. (1936). Über den Wahn bei Epilepsie. Zeitschıift für die gesamte Neurologie und Psychiatrie, 154, 395-399.

Gur, R. E. (1977). Motoric laterality imbalance in schizophrenia. Archives of General Psychiatry, 34, 33-37.

Hill, D. (1953). Psychiatric disorders of epilepsy. Medical Press (London), 20, 473-475.

James, I. P. (1960). Temporal lobectomy for psychomotor :pilepsy. Journal of Mental Science, 106, $543-558$

Janz, D. (1969). Die Epilepsien, pp. 274-300. Georg Thieme: Stuttgart.

Jensen, I. (1975a). Temporal lobe surgery around the world. Results, complications, and mortality. Acta Neurologica Scandinavica, 52, 354-373.

Jensen, I. (1975b). Temporal lobe epilepsy. Late mortality in patients treated with unilateral temporal resection. Acta Neurologica Scandinavica, 52, 374-380.

Jensen, I. (1975c). Genetic factors in temporal lobe epilepsy. Acta Neurologica Scandinavica, 52, 381394.

Jensen, I. (1976a). Temporal lobe epilepsy. Etiological factors and surgical results. Acta Neurologica Scandinavica, 53, 103-118.

Jensen, I. (1976b). Temporal lobe epilepsy. Types of seizures, age and surgical results. Acta Neurologica Scandinavica, 53, 335-357.

Jensen, I. (1976c). Temporal lobe epilepsy. Social conditions and rehabilitation after surgery. Acta Neurologica Scandinavica, 54, 22-44.

Jensen, I. (1977). Temporal lobe epilepsy. With special reference to surgical results, neuropathology, and social conditions. Danish Medical Bulletin, 24, 235251.

Jensen, I., and Klinken, L. (1976). Temporal lobe epilepsy and neuropathology. Histological findings in resected temporal lobes correlated to surgical results and clinical aspects. Acta Neurologica Scandinavica, 54, 391-414.

Jensen, I., and Larsen, J. K. (1979). Mental aspects of temporal lobe epilepsy. Follow-up of 74 patients after resection of a temporal lobe. Journal of Neurology, Neurosurgery, and Psychiatry, 42, 256-265.
Jensen, I., and Seedorff, H. H. (1976). Temporal lobe epilepsy and neuro-ophthalmology. Ophthalmological findings in 74 temporal lobe resected patients. Acta Ophthalmologica, 54, 827-841.

Jensen, I., and Værnet, K. (1977). Temporal lobe epilepsy. Follow-up investigation of 74 temporal lobe resected patients. Acta Neurochirurgica, 37, 173-200.

Juul-Jensen, P. (1964). Epilepsy. A clinical and social analysis of 1020 adult patients with epileptic seizures. Acta Neurologica Scandinavica, 40, Supplementum 5.

Juul-Jensen, P. (1974). Social prognosis. In Handbook of Clinical Neurology, vol. 15, pp. 800-814. Edited by P. J. Vinken and G. W. Bruyn. North-Holland: Amsterdam.

Kendrick, J. F., and Gibbs, F. A. (1957). Origin, spread and neurcsurgical treatment of the psychomotor type of seizure discharge. Journal of Neurosurgery, 14, 270-284.

Köhler, G. K. (1973). Epileptische Psychosen. Fortschritte der Neurologie, Psychiatrie und Ihrer Grenzgebiete, 41, 496-509.

Krapf, E. (1928). Epileptic und schizophrenie. Archiv für Psychiatrie und Nervenkrankheiten, 83, 547586.

Kristensen, O., and Sindrup, E. H. (1978). Psychomotor epilepsy and psychosis. I. Physical aspects. Acta Neurologica Scandinavica, 57, 361-369.

Landholt, H. (1960). Die Temporallappenepilepsie und ihre Psychopathologie. Biblioiheca Psychiatrica et Neurologica. Supplementa ad Psychiatria et Neurologia, Fasc. 112, pp. 1-102. S. Karger: Basel.

Meduna, L. von (1937). Die Konvulsionstherapie der Schizophrenie, pp. 1-121, Marhold: Halle.

Paillas, J. E. (1958). Aspects cliniques de l'epilepsie temporale. In Temporal Lobe Epilepsy, pp. 411439. Edited by M. Baldwin and P. Bailey. Charles C. Thomas: Springfield, Illinois.

Pond, D. A. (1957). Psychiatric aspects of epilepsy. Journal of the Indian Medical Profession, 3, 14411459.

Reitan, R. M. (1974). Psychological testing of epileptic patients. In Handbook of Clinical Neurology, vol. 15, pp. 559-575. Edited by P. J. Vinken and G. W. Bruyn. North-Holland: Amsterdam.

Rodin, E. A. (1968). The Prognosis of Patients with Epilepsy, pp. 455. Charles C. Thomas: Springfield, Illinois.

Rodin, E., De Jong, R. N., Waggonen, R. W., and Baggchi, B. K. (1957). Relationship between certain forms of psychomotor epilepsy and schizophrenia. Archives of Neurology and Psychiatry (Chicago), 77, 449-463.

Scott, D. F. (1978). Psychiatric aspects of epilepsy. British Journal of Psychiatry, 132, 417-430.

Serafetinides, E. A., and Falconer, M. A. (1962). The effects of temporal lobectomy in epileptic patients with psychosis. Journal of Mental Science, 108, 584-593.

Slater, E., and Beard, A. W. (1963a). The 
schizophrenia-like psychoses of epilepsy. 1. Psychiatric aspects. British Journal of Psychiatry, 109, 95-112.

Slater, E., and Beard, A. W. (1963b). The schizophrenia-like psychoses of epilepsy. 5. Discussion and conclusions. British Journal of Psychiatry, 109, 143-150.

Slater, E., and Glithero, E. (1963). The schizophrenialike psychoses of epilepsy. 2. Genetical aspects. British Journal of Psychiatry, 109, 130-133.

Strömgren, E. (1938). Beiträge zur psychiatrischen Erblehre, pp. 1-260. Ejnar Munksgaard: København.

Taylor, D. C. (1972). Mental state and temporal lobe epilepsy. Epilepsia, 13, 727-765.

Taylor, D. C. (1975). Factors influencing the occurrence of schizophrenia-like psychoses in patients with temporal lobe epilepsy. Psychological Medicine, 5, 249-254.

Taylor, D. C., and Falconer, M. A. (1968). Clinical, socioeconomic, and psychological changes after temporal lobectomy for epilepsy. British Journal of Psychiatry, 114, 1247-1261.

Torrey, E. F., and Peterson, M. R. (1974). Schizophrenia and the limbic system. Lancet, 2, 942-946.

Van Buren, J. M., Ajmone-Marsan, C., Mutsuga, N., and Sadowsky, D. (1975). Surgery of temporal lobe epilepsy. Advances in Neurology, 8, 155-196.

Yde, A., Lohse, E., and Faurbye, A. (1941). On the relation between schizophrenia, epilepsy and induced convulsions. Acta Psychiatrica et Neurologica Scandinavica, 16, 325-388. 